\title{
Effect of epidemiological treatment of contacts in preventing recurrences of non-gonococcal urethritis
}

\author{
M R FITZGERALD \\ From the Department of Genitourinary Medicine, The Royal Infirmary, Sheffield
}

SUMMARY Clinical investigations of the usefulness of routine epidemiological treatment of sexual contacts of men with non-gonococcal urethritis (NGU) have produced conflicting results that could have been due to the selection of patients. In this study, which was undertaken in a provincial city, 100 men with untreated sexual partners and 100 demographically similar men with treated sexual partners were reviewed for recurrences of NGU over 12 months. Prolonged courses of tetracyclines were found to be beneficial particularly when the sexual partner gave positive results to tests for chlamydiae. There was, however, no clinical evidence that the men benefited from routine epidemiological treatment of their sexual partners.

\section{Introduction}

Non-gonococcal urethritis (NGU) continues to be difficult to define and to treat, in spite of advances in the understanding of the aetiological role of Chlamydia trachomatis and mycoplasmas. The number of cases reported yearly in men continues to rise, and increased in the United Kingdom from 59023 in $1971^{1}$ to 86896 in $1981 .^{2}$ This implies the existence of an increasing reservoir of infection in the female population. As there is little agreement on the clinical features of non-specific genital infection (NSGI) in women, however, treatment is frequently offered on an epidemiological basis-that is, to sexual contacts without or before confirmation that they are infected. ${ }^{3}$ Such treatment is given in $\mathbf{7 6 . 3 \%}$ of clinics in the United Kingdom, although in only $54 \%$ of these is it given to most patients. This is because of differing opinions of the value of epidemiological treatment and the few investigations performed since tetracyclines became the almost universal treatment for non-specific urethritis (NSU) came to contradictory conclusions. ${ }^{4-7}$ Not all these studies were able to surmount certain practical difficulties of trial design: patients with previous urethritis need to be excluded, as a salient feature of the disease is its chronicity; all patients must have taken at least part of their treatment simultaneously with their sexual partners to prevent immediate re-

\footnotetext{
Address for reprints: Dr $\mathbf{M}$ FitzGerald, Department of Genitourinary Medicine, Addenbrooke's Hospital, Hills Road, Cambridge CB2 2QQ

Accepted for publication 24 January 1984
}

infection; and the relevance of default from follow up must be assessed.

Routine epidemiological treatment was introduced in Sheffield during 1979 for all female partners of men attending the department of genitourinary medicine, but without any other important change in treatment policy. I undertook this study to evaluate the effectiveness of epidemiological treatment by comparing the outcome in matched groups of men treated before and after this date.

\section{Patients and methods}

\section{STUDY POPULATION}

The population of Sheffield is particularly suitable for studies requiring prolonged follow up as it is very stable, with a mean outward migration over the years $1975-80$ of $25 \cdot 7 / 1000$ for a population of 543700 (National Health Service Central Register, Office of Population Censuses and Surveys, personal communication). Patients have access to only one clinic for the treatment of sexually transmitted diseases (STD), and it was assumed that, having presented with their first symptoms, they would return if their symptoms recurred. All patients studied were permanently resident in Sheffield at the time of first attendance; they were men with their first ever episode of urethritis of any sort, who described only heterosexual contact, and who were not taking antibiotics for any other reason.

Two groups of patients were compared: the first 100 men with NGU attending in 1978 whose contacts had not been given treatment, and the first 100 men attending in 1980 whose contacts had been treated 
epidemiologically. Both groups (1980 figures in brackets) were similar in age and country of origin: average age was $27 \cdot 7(27 \cdot 4)$, range $17-52(17-52) ; 90$ (89) had been born in the United Kingdom, six (seven) in the West Indies, and four (four) elsewhere. No attempt was made to compare duration of discharge, type of discharge, or results of urine analysis and microscopy, as these had been found to be unimportant in predicting outcome by previous workers. ${ }^{468}$ Numbers of sexual partners in the three months before treatment were similar in the two groups: 52 (50) had had one, 37 (41) two, and 10 (nine) three or more. (One patient seen in 1978 denied having had any sexual partner in the preceding three months). In 1980 only men whose partners had started treatment within 21 days of the start of their own treatment were studied, thus ensuring some overlap in the time when the couple was treated. In fact the average delay was $4 \cdot 3$ days.

\section{INITIAL EVALUATION}

The presence of urethritis was established after clinical examination, examination and microscopy of urine, and culture of urethral smears. The diagnosis of NGU was made on the basis of eight or more polymorphonuclear leucocytes per high power field at $\times 700$ magnification (10 fields being examined), negative results on microscopy and culture for Neisseria gonorrhoea, negative wet mount microscopy results for Trichomonas vaginalis and yeasts, and the absence of clinical signs of intrameatal warts or genital herpes. All patients had negative serological test results for syphilis. There was no change in diagnostic criteria between the years studied, and criteria for retreatment were similar.

The female sexual partners all had a genital examination, which included inspection of the cervix and vagina using a speculum and bimanual pelvic examination. The following tests were carried out routinely: microscopy of smears from the urethra and endocervical canal; culture of swabs from the urethra and cervix for $N$ gonorrhoeae; dark ground microscopy of vaginal wet mount preparations for $T$ vaginalis and yeast; and (in 1980) culture of swabs from the cervix for $\boldsymbol{C}$ trachomatis. In addition full blood counts and serological tests for syphilis were performed routinely. Specimens for isolation of $C$ trachomatis were transported in a medium containing sorbitol, vancomycin, streptomycin, and mycostatin, inoculated into monolayers of McCoy cells sterilised with idoxuridine, and grown on coverslips in flat bottomed tubes. Inoculation was achieved by centrifuging at $3000 \times g$ for one hour at $35^{\circ} \mathrm{C}$ and was followed by incubation at $17^{\circ} \mathrm{C}$ for 48 hours in a maintainance medium with added amphotericin B. Cells were then fixed in methanol, stained with Giemsa, and examined for inclusion bodies by dark ground microscopy.

\section{TREATMENT}

Women in whom no specific organism had been found by the microscopical methods described above were treated routinely as contacts of men with NSU. Almost all received triple tetracycline (Deteclo 300 mg) (Lederle, Gosport, Hampshire) twice daily for two weeks, or the same dose of erythromycin if pregnancy was a possibility. (One $300 \mathrm{mg}$ tablet of Deteclo contains chlortetracycline hydrochloride $115.4 \mathrm{mg}$, tetracycline hydrochloride $115.4 \mathrm{mg}$, demeclocycline hydrochloride $69.2 \mathrm{mg}$; erythromycin was given as Erythrocin 500 (Abbott, Queenborough, Kent)).

The men were all offered three weeks' treatment, the tablets being dispensed at weekly visits to check on response and assist compliance, but naturally some men defaulted before they had received the whole course. Nearly all were treated with tetracyclines, most with triple tetracycline, although if the immediate response was unsatisfactory a change of antibiotic was made. Of the patients seen in 1978, 93 were treated with triple tetracycline, and seven with oxytetracycline; of those seen in in 1980 , 91 were treated with triple tetracycline, eight with oxytetracycline, and one with erythromycin. Of the patients treated with triple tetracycline, three of those seen in 1978 and six of those seen in 1980 were later treated with oxytetracycline or erythromycin.

\section{FOLLOW UP}

The follow up after the end of treatment depended on the circumstances of the individual case, most patients being asked to reattend after two weeks and then after two months. Nevertheless, for reasons given earlier, it was assumed that patients who had further symptoms would reattend the clinic for assessment. The case records of all the patients were therefore examined for 12 months after the start of treatment, and their subsequent progress was analysed. To make comparisons with other work possible, the index of relapse or reinfection used was "recurrence requiring retreatment", in common with most other studies of NSU. 4-6910

The average total attendance at the clinic was $20 \cdot 4$ weeks in 1978 and 14 weeks in 1980 , these figures being calculated from the start of treatment to the last date the patient was seen at the clinic for any reason, allowing a maximum attendance of 52 weeks. These figures therefore reflect the stability of the Sheffield population and its willingness to attend, rather than the duration of the illness or follow up requested. 
TABLE I Number of retreatment episodes of non-gonococcal urethritis in 200 men

\begin{tabular}{|c|c|c|c|c|}
\hline \multirow{3}{*}{$\begin{array}{l}\text { Months after start } \\
\text { of first treatment }\end{array}$} & \multicolumn{2}{|c|}{$\begin{array}{l}\text { Men with contacts } \\
\text { not treated }(n=100)\end{array}$} & \multirow{2}{*}{\multicolumn{2}{|c|}{$\begin{array}{l}\text { Men with treated contacts }(n=100) \\
\text { (No of patients/episodes when } \\
\text { contact had chlamydial infection) }\end{array}$}} \\
\hline & \multirow{2}{*}{$\begin{array}{l}\text { No of } \\
\text { patients }\end{array}$} & \multirow{2}{*}{$\begin{array}{l}\text { No of } \\
\text { episodes }\end{array}$} & & \\
\hline & & & No of patients & No of episodes \\
\hline $\begin{array}{r}3 \\
6 \\
12\end{array}$ & $\begin{array}{l}11 \\
15 \\
21\end{array}$ & $\begin{array}{l}13 \\
18 \\
30\end{array}$ & $\begin{array}{r}8(1) \\
16(4) \\
20(6)\end{array}$ & $\begin{array}{l}12(2) \\
22(5) \\
31(7)\end{array}$ \\
\hline
\end{tabular}

Results

A total of 100 men with untreated sexual contacts and 100 with treated sexual contacts were reviewed for recurrences of NGU during the 12 months after their initial treatment. Out of about 160 contacts listed by index cases, 113 received treatment. The disparity was due to the proportion of casual partners who did not attend, even though the principal partner did receive treatment. Table I shows the effect of treatment of sexual contacts on the need for retreatment of index cases. When assessed over 12 months, the number of retreatment episodes and the number of patients being retreated was almost identical in the two groups, with about $20 \%$ of the patients returning for further treatment. At three months there was a small difference in favour of men whose sexual contacts had been treated, eight of whom needed retreatment compared with 11 in the group in which only the index case had been treated.

Recurrences in the first three months are the most important, as later recurrences more often follow exposure to new partners. After six to 12 months, at least $70 \%$ of the men seen in 1978 had had a new sexual partner, as had all the patients who were retreated after six to 12 months in 1980 . If recurrence is due to reinfection, it could be expected that the retreatment rate in men with untreated contacts would be higher when they are in a regular relationship than when the relationship is casual. All the patients were asked about the duration of their relationships in the preceding three months, and relationships lasting six weeks or more were classed as regular. Of the men seen in 1978, 31 had had a

TABLE II Retreatment episodes over 12 months related to numbers of sexual contacts in six weeks before first treated

\begin{tabular}{|c|c|c|c|c|}
\hline \multirow{2}{*}{$\begin{array}{l}\text { No of contacts } \\
\text { in six months } \\
\text { before first } \\
\text { ireatiment }\end{array}$} & \multicolumn{2}{|c|}{$\begin{array}{l}\text { Men with contacts } \\
\text { not treated }(n=100)\end{array}$} & \multicolumn{2}{|c|}{$\begin{array}{l}\text { Men with treated } \\
\text { contacts }(n=100)\end{array}$} \\
\hline & $\begin{array}{l}\text { No of } \\
\text { patients }\end{array}$ & $\begin{array}{l}\text { No }(\%) \text { of } \\
\text { episodes }\end{array}$ & $\begin{array}{l}\text { No of } \\
\text { patients }\end{array}$ & $\begin{array}{l}\text { No }(\%) \text { of } \\
\text { episodes }\end{array}$ \\
\hline $\begin{array}{l}1 \\
2 \\
3\end{array}$ or more & $\begin{array}{l}53 \\
37 \\
10\end{array}$ & $\begin{array}{c}5(9 \cdot 5) \\
13(35) \\
3(30)\end{array}$ & $\begin{array}{r}50 \\
41 \\
9\end{array}$ & $\begin{array}{r}6(12) \\
11(27) \\
3(33)\end{array}$ \\
\hline
\end{tabular}

"casual" relationship and four (13\%) of them required treatment at three months; whereas 65 were in a "regular" relationship and seven (11\%) of them required treatment. (The status of the four other patients was not known.) Table II shows that in both groups of men similar numbers had had more than one sexual contact in the six weeks before initial treatment, and that this had an appreciable bearing on the numbers of recurrences.

Retreatment rates $(12.5 \%$ in $1978,31 \%$ in 1980$)$ were higher in patients over 40 and men of West Indian origin (16\% in $1978,43 \%$ in 1980$)$, but the numbers in these categories were too small to allow clear conclusions to be drawn. Patients who were given short courses of treatment were much more likely to require retreatment, whether their contacts were treated or not. Of men seen in 1978 , six $(21 \%)$ out of the 28 patients given one or two weeks' treatment required further treatment within three months, compared with $7 \%$ of those treated for three weeks. The corresponding figures for men seen in 1980 was three $(18 \%)$ out of 17 compared with $7 \%$ of those treated for three weeks. By 1980, routine culture for $\boldsymbol{C}$ trachomatis had become available, and $29 \%$ of the 100 men studied had a contact from whom it was isolated. In the first three months, only one of these men $(3.5 \%)$ required retreatment, and he had had a new sexual partner. This compares with seven $(\mathbf{1 0 \%})$ out of 71 men in whom $C$ trachomatis was not isolated.

\section{Discussion}

Although the tracing and treatment of sexual contacts is an axiom in the treatment of most sexually transmitted infections, some workers still do not feel that it is necessary in NGU. The evidence for its being beneficial is scanty, and the studies done have been difficult to evaluate for the reasons mentioned earlier. This study also failed to show clear cut evidence that men benefit substantially from routine epidemiological treatment of their female sexual partners and confirms the conclusions of Evans, ${ }^{45}$ Morton and Read, ${ }^{8}$ and Rosedale. ${ }^{11}$ The study did not completely avoid some practical problems of execution: the possibility that patients might have been re-exposed to an untreated partner could not be 
excluded, even during the first three months; and complete follow up could not be guaranteed. It is most unlikely, however, that these problems could ever be eliminated other than for short periods under special conditions. ${ }^{12}$ Most clinicians are concerned about practical benefit to their patients and will be working under circumstances similar to those in which these patients were treated in Sheffield.

Treatment of NGU is difficult to evaluate because of the lack of a specific marker for the disease. When $C$ trachomatis can be shown to be a cause, NGU appears to be largely like other STDs, with response to treatment in men, ${ }^{13}$ isolation from female partners, ${ }^{14} 15$ and persistence in unsuccessfully treated cases. ${ }^{16} C$ trachomatis causes only a proportion of NGU but response to treatment in such cases is much more satisfactory. ${ }^{13}$ This study also showed a good response in patients whose partners yielded $C$ trachomatis. The satisfactory response to treatment should amply justify contact tracing, routine culture, and treatment of sexual partners of patients in whom $C$ trachomatis is isolated. It might also in itself be justification for routine epidemiological treatment of women in circumstances where culture for $C$ trachomatis is not available.

Most clinics in the United Kingdom now treat NGU with tetracyclines, but there are differences in the duration of treatment, and most use a five to seven day course. ${ }^{17}$ Our findings show an appreciable benefit from a longer course of treatment, but the shorter course represents a failure of compliance and recurrences may have been due to other factors.

I was also able to show a striking increase in recurrences in patients who have more than one partner, whether their principal partner was treated or not. It is possible that this is due to the increased chance that such men may later be reinfected from another source, but it in any case suggests that the key to preventing recurrence of NGU lies with the sexual contacts. The most perplexing finding was that, for men whose partners were untreated, recurrence was not strikingly different whether the patients were in regular or casual relationships. We clearly cannot expect epidemiological treatment to improve the recurrence rate beyond that found when no further exposure occurs. Perhaps this finding only highlights the weakness of our present clinical methods of assessing NGU. The symptoms and signs that have to be relied on may not correlate with the presence of any infectious agent, and antibiotic treatment may not always be appropriate. It has been shown that chlamydiae may be present in the male urethra without causing symptoms, ${ }^{18}{ }^{19}$ and that even mycoplasmas may cause a reaction which continues long after the organisms have been eradicated. ${ }^{20}$

This study shows that treatment with three week courses of tetracyclines is beneficial to men with NGU, particularly those whose sexual partners have chlamydial infections, but it is difficult to produce clinical evidence that the men benefit from routine epidemiological treatment of their sexual contacts. The possibility remains that epidemiological treatment may be shown to be worthwhile when more precise tests for NGU are available.

I thank Dr G R Kinghorn, who has been generous with advice and encouragement at every stage of this work.

\section{References}

1. Annual report of the Chief Medical Officer of Health for 1971. Department of Health and Social Security. London: HMSO, 1972.

2. Annual report of the Chief Medical Officer of Health for 1981 . Department of Health and Social Security. London: HMSO, 1982.

3. Adler MW. Diagnostic, treatment, and reporting criteria for non-specific genital infection in sexually transmitted disease clinics in England and Wales: 1 Diagnosis. $\mathrm{Br} J$ Vener Dis 1978; 54: 422-7.

4. Evans BA. The role of tetracyclines in the treatment of nonspecific urethritis. $\mathrm{Br} J$ Vener L'is 1977;53:40-3.

5. Evans BA. Treatment and prognosis of non-specific genita infection. Br J Vener Dis 1978; 54: 107-11.

6. Arya OP, Alergant CD, Annels EH, Carey PB, Ghosh AK, Goddard AD. Management of non-specific urethritis in men. Br J Vener Dis 1978;54:414-21.

7. Thambar IV, Simmons PD, Thin RN, Darougar S, Yearsley P Double-blind comparison of two regimens in the treatment of non-gonococcal urethritis. Br J Vener Dis 1979; 55:284-8.

8. Morton RS, Read L. Non-gonococcal urethritis: an investigation to determine factors in the host influencing response to treatment and recu. rence of symptoms. $\mathrm{Br} J \mathrm{Vener}$ Dis 1957; 33:223-7.

9. Willcox RR, Sparrow RW, Fazluddin CM. Minocycline in the treatment of non-gonococcal urethritis. $\mathrm{Br} J$ Vener Dis 1975;51:206-9.

10. Bhattacharyya $\mathrm{MN}$, Morton RS. Long term triple tetracycline ('Deteclo') treatment of non-specific urethritis. Br J Vener Dis 1973; 49:521-3.

11. Rosedale N. Female contacts of men with non-gonococcal urethritis. $\mathrm{Br} J$ Vener Dis 1959; 35:245-8.

12. Holmes KK, Johnson DW, Floyd TM. Double-blind comparison of tetracycline hydrochloride and placebo in treatment of non-gonococcal urethritis. JAMA 1967;202: 474-6.

13. Handsfield $\mathrm{HH}$, Alexander ER, Wang SP, Pedersen AHB Holmes KK. Differences in the therapeutic response of chlamydia-positive and chlamydia-negative forms of nongonococcal urethritis. Journal of the American Venereal Disease Association 1976; 2:5-9.

14. Dunlop EMC, Vaughan-Jackson JD, Darougar S, Jones BR. Chlamydial infection: incidence in 'non-specific' urethritis. $\mathrm{Br}$ $J$ Vener Dis 1972; 48:425-8.

15. Oriel JD, Reeve P, Powis P, Miller A, Nicol CS. Chlamydia infection: isolation of chlamydia from patients with nonspecific genital infection. Br J Vener Dis 1972;48:429-36.

16. Lassus A, Paavonen J, Konsa M, Saikku P. Erythromycin and lymecycline treatment in chlamydia-positive and chlamydianegative non-gonococcal urethritis-a partner controlled study. Acta Derm Venereol 1979;59:278-81.

17. Adler MW. Diagnostic, treatment, and reporting criteria for non-specific genital infection in sexually transmitted disease in clinics in England and Wales: 2 Treatment and reporting criteria. Br J Vener Dis 1978;54:428-32.

18. Holmes KK, Handsfield HH, Wang SP, et al. Etiology of nongonococcal urethritis. N Engl J Med 1975; 292: 1199-206.

19. Oriel JD, Reeve P, Wright JT, Owen J. Chlamydial infection of the male urethra. Br J Vener Dis 1976;52:46-51.

20. Taylor-Robinson D, Csonka GW, Prentice MJ. Human intraurethral inoculation of ureaplasma. $Q J$ Med 1977; 46: 309-26. 